\title{
Realidad laboral del egresado de la licenciatura en Canto de la Universidad Autónoma de Zacatecas
}

\author{
Labor reality of the graduate of the bachelor's degree in voice of the \\ Autonomous University of Zacatecas
}

\section{Realida de trabalhista do graduado do Bacharelado em Canto pela Universidade Autônoma de Zacatecas}

\author{
Solanye Caignet Lima \\ Universidad Autónoma de Zacatecas, México \\ solanye.caignet@gmail.com \\ https://orcid.org/0000-0002-5559-2088
}

\section{Resumen}

La licenciatura en Canto de la Unidad Académica de Artes de la Universidad Autónoma de Zacatecas (UAA-UAZ), con una duración de cuatro años en el nuevo plan de estudios, se estructuró con base en las necesidades formativas del estudiante. La UAA-UAZ ha trabajado durante años para hacerse pertinente como opción principal para la formación de estudiantes de canto. Diversos cantantes han egresado de esta licenciatura con el firme propósito de convertirse en hábiles y eficientes exponentes del Canto. Sin embargo, una vez titulado, el nuevo licenciado en Canto se ha encontrado con un panorama laboral limitado y complejo. En tal sentido, en esta investigación se comprobó el comportamiento del mercado laboral en el ámbito del canto en general. También se comprobó la vinculación que existe entre las materias del currículo de la licenciatura en Canto, así como la carencia de otras necesarias para alcanzar un mejor perfil de egreso. Los objetivos perseguidos fueron el diagnóstico y análisis general del plan de estudio actual y el perfil de egreso, aspectos que inciden en la continuidad hacia la inserción laboral. Se encontró que un interesante porcentaje de artistas 


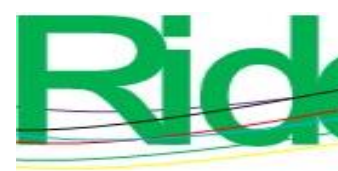

Revista Iberoamericana para la Investigación y el Desarrollo Educativo ISSN $2007-7467$

que se dedican a las bellas artes en el país se autoemplean. De hecho, la información recabada con una encuesta demuestra inconsistencias con los resultados del currículo de la licenciatura en Canto, así como con las exigencias de un mercado laboral inestable. Asimismo, los profesionales del arte que están ocupados durante el año a nivel nacional representan un bajo porcentaje en la tabla de encuesta del observatorio laboral. Se concluye, por tanto, que la licenciatura en Canto presenta una desconexión con el mercado laboral, la cual es generada por políticas educativas y culturales que deben ser revisadas.

Palabras claves: currículo, licenciatura en Canto, mercado laboral, perfil de egreso.

\section{Abstract}

The Bachelor of Singing of the Arts Units of the Autonomous University of Zacatecas (UAAUAZ) with a duration of five years in the new study plan, was structured based on the student's training needs.

The UAA-UAZ, has worked through many years to become relevant as the main option for the training of singing students. Various singers have graduated from this Degree with the firm intention of becoming skilled and efficient exponents of the singing. Once graduated, the new Bachelor of Singing has found a limited and extremely complicated job outlook.

In this investigation the behavior of the Labor Market in the field of Singing in general was verified. The link between the subjects of the Bachelor's Degree in Singing curriculum was also verified, as well as the lack of others which are necessary to achieve a new and improved graduation profile. The objectives that are pursued are the diagnosis and general analysis of the current study plan and the graduation profile that affect the continuity towards labor insertion.

It was found that an interesting percentage of artists who dedicate themselves to the Fine Arts in the country are self-employed. The results of the survey show disagreement with the results of the Bachelor's degree in Singing, as well as the demands of an unstable labor market. Art professionals who are employed during the year at the national level represent a low percentage in the survey table of the Labor Observatory.

It is concluded that the Bachelor in Singing presents a disconnection in itself and towards the labor market but that actions continue to be exercised to enhance the profile of graduation. This disconnection is based on several measurement parameters. Educational and cultural policies are also variable in how much the artistic proceeds of the state singers. 


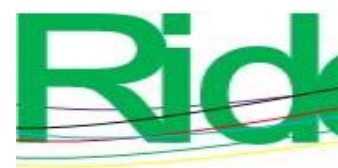
Revista Iberoamericana para la
Investigación y el Desarrollo Educativo
ISSN $2007-7467$

Keywords: curriculum, Bachelor's degree in voice, labor market, graduation profile.

\section{Resumo}

O Bacharelado em Canto pela Unidade Acadêmica de Artes da Universidade Autônoma de Zacatecas (UAA-UAZ), com duração de quatro anos no novo currículo, foi estruturado em função das necessidades de formação do aluno. A UAA-UAZ trabalha há anos para se tornar relevante como principal opção para a formação de estudantes de canto. Vários cantores se formaram neste grau com a firme intenção de se tornarem expoentes habilidosos e eficientes do Canto. No entanto, uma vez formado, o novo Bacharel em Canto encontrou uma visão de trabalho limitada e complexa. Nesse sentido, esta pesquisa verificou o comportamento do mercado de trabalho na área de canto em geral. Verificou-se também a vinculação entre as disciplinas do currículo do Bacharelado em Canto, bem como a falta de outras necessárias para alcançar um melhor perfil de graduação. Os objetivos perseguidos foram o diagnóstico e a análise geral do plano de estudos em curso e do perfil da graduação, aspectos que condicionam a continuidade da inserção laboral. Verificou-se que um percentual interessante de artistas que se dedicam às artes plásticas no país são autônomos. De fato, as informações obtidas em uma pesquisa mostram inconsistências com os resultados do currículo do curso de bacharelado em canto, bem como com as demandas de um mercado de trabalho instável. Da mesma forma, os profissionais de arte que trabalham durante o ano a nível nacional representam uma percentagem baixa na tabela de sondagem do observatório do trabalho. Conclui-se, portanto, que o bacharelado em canto apresenta um descompasso com o mercado de trabalho, gerado por políticas educacionais e culturais que devem ser revistas.

Palavras-chave: currículo, bacharelado em canto, mercado de trabalho, perfil da graduação.

Fecha Recepción: Octubre 2020

Fecha Aceptación: Mayo 2021 


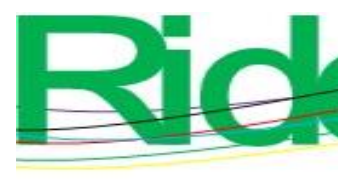

Revista Iberoamericana para la Investigación y el Desarrollo Educativo ISSN $2007-7467$

\section{Introducción}

El interés por este tema de investigación surgió por una inquietud personal y comunitaria dentro del mundo artístico-vocal. Por esta razón, la presente es una indagación de corte empírico y observacional dentro de un contexto académico y artístico. El énfasis se ha puesto en la desconexión entre el perfil de egreso de la licenciatura en Canto de la Unidad Académica de Artes de la Universidad Autónoma de Zacatecas (UAA-UAZ) y las necesidades de un incipiente mercado laboral en el país y en el extranjero.

Zacatecas es un estado fundamentalmente cultural y ha sido nombrado capital de la cultura para el año de 2021, como lo señala Porras (1 de octubre de 2019):

México se coloca al frente con las designaciones de Capital Americana de la Cultura. En el 2000 fue otorgado a Mérida; 2005 a Guadalajara; 2014 al Estado de Colima; 2017 nuevamente a Mérida; 2019 a San Miguel de Allende; y 2021 a Zacatecas (Porras, 2019, párr. 9).

Esta es una ciudad que exalta la cultura, elemento sumamente importante dentro del contexto social y que puntualiza su futura trascendencia. Según Benzecry (2012), “el objetivo es construir una sociología del apego a formas culturales centrada en el carácter afectivo y personalizado de esa afición y analizar, en la búsqueda de claves, la cuestión de la autoformación y la autotrascendencia” (p. 33).

De manera general, la creación de una escuela de música en Zacatecas fue un curso predecible dentro de la panorámica cultural del estado y ha sido un total acierto, ya que ha formado a licenciados en Música con énfasis en canto e instrumento tanto de Zacatecas como de los estados aledaños. Bajo la rectoría del Lic. Jorge Eduardo Hiriart Estrada, se creó la primera escuela de artes, donde se impartían diferentes disciplinas. Entre sus fundadores se pueden nombrar maestros como José A. Rincón, Jesús González, Luis Félix Serrano, Jesús González Córdoba, entre otros.

En el año de 1987 se creó un convenio con Cuba bajo la dirección del Mtro. Esaúl Arteaga. Se gestionó la llegada de maestros cubanos que colaborarían para elevar el nivel de la enseñanza musical en Zacatecas. Los primeros profesores cubanos que llegaron en el año de 1991 fueron los maestros Rodolfo Navarro y Luis Bayard, chelista y flautista, respectivamente. $\mathrm{Al}$ año siguiente arribaron a la ciudad de Zacatecas el pianista y pedagogo Cesar López Zarragoitia, la violista Mara Lioba Juan Carvajal y la cantante de ópera y pedagoga Ninón Lima Guerrero. Así surgió la Academia de Canto de la Escuela de Música 


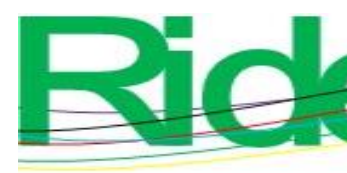
Revista Iberoamericana para la
Investigación y el Desarrollo Educativo
ISSN $2007-7467$

en el año de 1992, con los maestros Héctor Mora, cantante zacatecano, y Ninón Lima, reconocida soprano cubana que tuvo una prominente carrera como cantante de ópera y concierto a nivel nacional e internacional. Sobre ella Hernández (2020) comenta:

La descrita multiplicidad de funciones artísticas y estilísticas de Ninón Lima, conjuntamente con la profunda dimensión de su formación profesional, sin dudas definieron y permitieron el nacimiento y desarrollo de una pedagoga del canto, particular en su esencia, precisamente por considerar el canto en una dimensión humana y artística, sin prejuicios, ni elitismo (Hernández, 2020, párr. 13).

Como docente fue fundadora del Instituto Superior de Artes (ISA) de La Habana, en donde fungió como maestra de canto por más de treinta años. Como resultado de esta enseñanza, se titularon valiosos cantantes que después fueron parte importante del panorama lírico de Cuba y Estados Unidos. La enseñanza de la maestra Ninón Lima estaba estructurada sobre unas bases sólidas de la técnica europea del canto lírico, la cual se fundaba en la firmeza del apoyo del sonido y su brillantez a través de la resonancia. "Su concepto ecuménico de la enseñanza del canto le permitió, en la selección del repertorio, transgredir reglas impuestas por los tiempos y costumbres ajenas a nuestra cultura" (Hernández, 2020, párr.18) Durante su función como docente, egresaron aproximadamente veinte cantantes. Cuatro de ellos son los actuales maestros de canto de la unidad. La figura de una nueva cátedra de maestros cubanos en Zacatecas determinó el proceso de afianzamiento de la enseñanza musical de calidad en la universidad.

Ahora bien, el plan de estudios de la actual licenciatura en Canto se ha ido restructurando con el paso de los años. Los maestros de la academia que la han integrado continúan trabajando para ajustarlo al contexto estatal y nacional. De acuerdo con un sondeo informativo en las oficinas administrativas dentro de la unidad, la licenciatura cuenta con alrededor de cincuenta egresados. Fue reestructurada por primera vez en el año 2011. Está avalada por los Comités Interinstitucionales para la Evaluación de la Educación Superior (CIEES) en el nivel uno y está en proceso de reacreditación por el Consejo para la Acreditación de la Educación Superior de las Artes (CAESA). Es un programa que está dirigido principalmente al cantante lírico o de ópera, y no a cantantes populares. Esto exige una revisión curricular de alta complejidad, pero necesaria, debido a la demanda que ha existido para este rubro. Además, como explica Polanco (2013), el sistema de enseñanza musical continúa con los parámetros del modelo educativo del siglo XIX: 


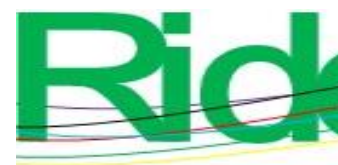

Revista Iberoamericana para la Investigación y el Desarrollo Educativo ISSN $2007-7467$

Los alumnos, forzados por el peso de la tradición y por unas estructuras educativas poco flexibles, se ven arrastrados hacia la interpretación, o en menor medida hacia la dirección o la composición, casi como únicas salidas profesionales. Pero, es más, la mayoría de los que escogen ser intérpretes lo hacen guiados por la exclusiva pretensión de ser concertistas o solistas de una orquesta sinfónica. Se adentran así, sin que sus preceptores puedan o quieran impedirlo, es un camino difícil y cada vez más estrecho que aboca a muchos de ellos a la frustración o al abandono, puesto que no logran alcanzar el grado de excelencia requerido para poder conseguir la meta anhelada. Los que, a pesar de todo, persisten en el intento sin lograr finalmente sus propósitos iniciales, acaban decantándose por la docencia como una opción laboral aparentemente más asequible (Polanco, 2013, párr. 21).

En el caso particular del cantante lírico, la demanda va en el sentido de la ópera o el recital. Estas brechas requieren de un análisis pormenorizado visto desde varios ángulos, en especial desde la visión externa de la profesión.

Explicado lo anterior, la pregunta de investigación planteada fue la siguiente: ¿cuáles son las relaciones entre la desconexión del perfil de egreso y la inserción al mercado laboral? Los objetivos que persigue esta investigación son estos:

- Diagnosticar las fortalezas y carencias de la licenciatura a través del análisis FODA.

- Analizar el panorama curricular general de la licenciatura.

- Comprobar las aristas del actual mercado laboral para cantantes.

- Proporcionar soluciones parciales y actuales dentro de la licenciatura en Canto de la Universidad Autónoma de Zacatecas que lleven a la menor desconexión posible con respecto al mercado laboral.

Esta, en definitiva, es una investigación mixta, de tipo exploratorio, con investigación documental y de campo, y con una muestra no probabilística obtenida por consenso de los 31 participantes. 
Figura 1. Mapa curricular de la licenciatura en Canto

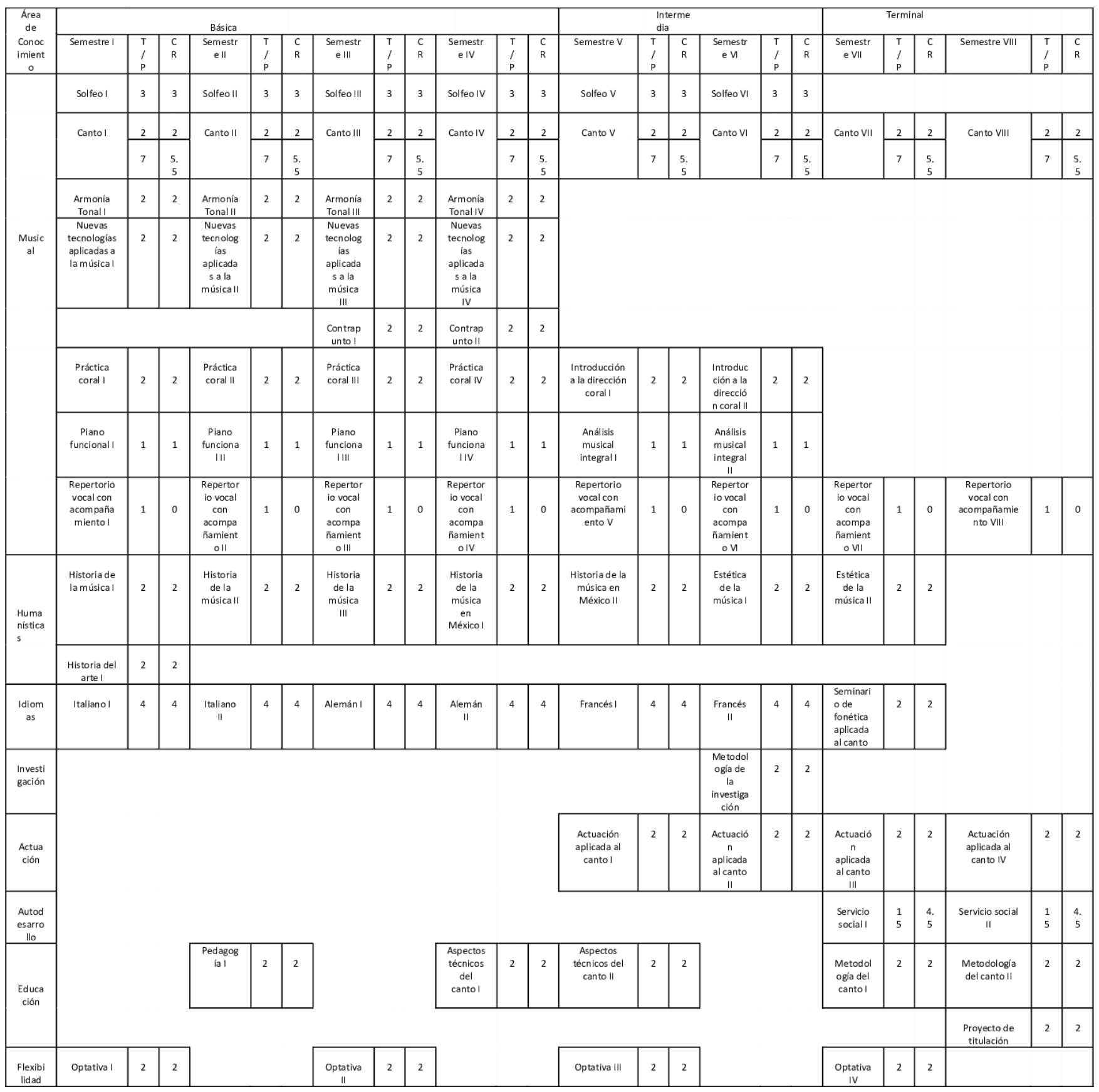

Fuente: Archivos digitales de la Unidad de Artes de la Universidad Autónoma de Zacatecas

Este mapa nos muestra algunas materias que son vinculatorias con el canto, como Actuación y Repertorio Vocal, así como materias de soporte teórico. El nombre de la materia Piano Funcional implica una cierta generalización, y no determina una completa interrelación con lo que el estudiante de canto necesita. Materias relacionadas con las nuevas tecnologías son prioritarias y hay pocos semestres del idioma italiano, una de las lenguas más pertinentes en el área de canto. Asimismo, no hay una materia de cámara o ensambles. La tabla 1 muestra 


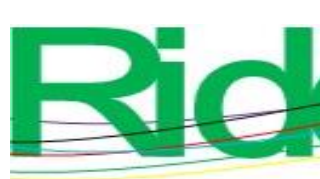

Revista Iberoamericana para la Investigación y el Desarrollo Educativo ISSN 2007 - 7467

las materias del mapa curricular de la licenciatura en Canto de la Universidad Autónoma de México (UNAM) que están vinculadas al canto.

Tabla 1. Materias vinculadas al canto en el mapa curricular de la licenciatura en Canto de la UNAM

\begin{tabular}{|c|c|c|c|c|c|c|c|c|}
\hline $\begin{array}{l}\text { Seme } \\
\text { stre }\end{array}$ & 1 & 2 & 3 & 4 & 5 & 6 & 7 & 8 \\
\hline $\begin{array}{l}\text { Crédit } \\
\text { os }\end{array}$ & 49 & 49 & 57 & 57 & 59 & 59 & 53 & 55 \\
\hline $\begin{array}{l}\text { Mater } \\
\text { ia }\end{array}$ & $\begin{array}{l}\text { Repert } \\
\text { orio } \\
\text { vocal } 1\end{array}$ & $\begin{array}{l}\text { Repert } \\
\text { orio } \\
\text { vocal } 2\end{array}$ & $\begin{array}{l}\text { Repert } \\
\text { orio } \\
\text { vocal } 3\end{array}$ & $\begin{array}{l}\text { Repert } \\
\text { orio } \\
\text { vocal } 4\end{array}$ & $\begin{array}{l}\text { Repertorio } \\
\text { vocal } 5\end{array}$ & $\begin{array}{l}\text { Repertor } \\
\text { io vocal } \\
6\end{array}$ & $\begin{array}{l}\text { Repert } \\
\text { orio } \\
\text { vocal } 7\end{array}$ & $\begin{array}{l}\text { Repert } \\
\text { orio } \\
\text { vocal } 8\end{array}$ \\
\hline $\begin{array}{l}\text { Mater } \\
\text { ia }\end{array}$ & $\begin{array}{l}\text { Melodi } \\
\text { e, Lied, } \\
\text { Música } \\
\text { mexica } \\
\text { na o } \\
\text { españo } \\
\text { la 1 }\end{array}$ & $\begin{array}{l}\text { Melodi } \\
\text { e, Lied, } \\
\text { Música } \\
\text { mexica } \\
\text { na o } \\
\text { españo } \\
\text { la } 2\end{array}$ & $\begin{array}{l}\text { Melodi } \\
\text { e, Lied, } \\
\text { Música } \\
\text { mexica } \\
\text { na o } \\
\text { españo } \\
\text { la } 3\end{array}$ & $\begin{array}{l}\text { Melodi } \\
\text { e, Lied, } \\
\text { Música } \\
\text { mexica } \\
\text { na o } \\
\text { españo } \\
\text { la } 4\end{array}$ & $\begin{array}{l}\text { Melodie, } \\
\text { Lied, } \\
\text { Música } \\
\text { mexicana } \\
\text { o española } \\
5\end{array}$ & $\begin{array}{l}\text { Melodie, } \\
\text { Lied, } \\
\text { Música } \\
\text { mexican } \\
\text { a o } \\
\text { española } \\
6\end{array}$ & $\begin{array}{l}\text { Melodi } \\
\text { e, Lied, } \\
\text { Música } \\
\text { mexica } \\
\text { na o } \\
\text { españo } \\
\text { la } 7\end{array}$ & $\begin{array}{l}\text { Melodi } \\
\text { e, Lied, } \\
\text { Música } \\
\text { mexica } \\
\text { na o } \\
\text { españo } \\
\text { la } 8\end{array}$ \\
\hline $\begin{array}{l}\text { Mater } \\
\text { ia }\end{array}$ & & & - & $\begin{array}{l}\text { Ópera } \\
\text { de } \\
\text { Cámar } \\
\text { a } 1\end{array}$ & $\begin{array}{l}\text { Ópera de } \\
\text { Cámara } 2\end{array}$ & & & \\
\hline $\begin{array}{l}\text { Mater } \\
\text { ia }\end{array}$ & $\begin{array}{l}\text { Piano } \\
\text { aplicad } \\
\text { o al } \\
\text { canto } 1\end{array}$ & $\begin{array}{l}\text { Piano } \\
\text { aplicad } \\
\text { o al } \\
\text { canto } 2\end{array}$ & $\begin{array}{l}\text { Piano } \\
\text { aplicad } \\
\text { o al } \\
\text { canto } 3\end{array}$ & $\begin{array}{l}\text { Piano } \\
\text { aplicad } \\
\text { o al } \\
\text { canto } 4\end{array}$ & $\begin{array}{l}\text { Psicopeda } \\
\text { gogía } \\
\text { musical }\end{array}$ & $\begin{array}{l}\text { Práctica } \\
\mathrm{s} \\
\text { docentes } \\
\text { supervis } \\
\text { adas }\end{array}$ & $\begin{array}{l}\text { Ópera } \\
\text { de } \\
\text { Cámar } \\
\text { a } 3 \text { o } \\
\text { Teatro } \\
\text { Musica } \\
11\end{array}$ & $\begin{array}{l}\text { Ópera } \\
\text { de } \\
\text { Cámar } \\
\text { a } 3 \text { o } \\
\text { Teatro } \\
\text { Musica } \\
11\end{array}$ \\
\hline
\end{tabular}




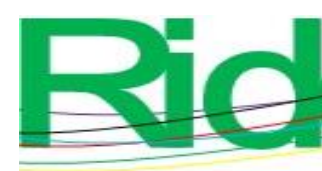

Revista Iberoamericana para la Investigación y el Desarrollo Educativo ISSN $2007-7467$

\begin{tabular}{|l|l|l|l|l|l|l|l|l|}
\hline Mater & Italian & Italian & Italian & Italian & francés o & Francés & Francé & - \\
ia & o 1 & o 2 & o 3 & o 4 & alemán 1 & o alemán & s & o \\
\end{tabular}

Fuente: Elaboración propia

En esta tabla, la materia de Repertorio Vocal es una constante y el idioma italiano aparece como prioritario. La materia de piano aparece como Piano Aplicado al Canto y como materias de elección: Lied, Melodie, Canción Mexicana o Española, que son de extrema importancia en la formación. Aparece una materia de Ópera de Cámara que ofrece más posibilidades para el repertorio operístico. Otra materia de primer orden es la de Prácticas Docentes Supervisadas, que da una orientación hacia la docencia.

En la tabla 2 se aprecia un extracto del mapa curricular de la licenciatura en Canto de la Universidad de Houston, Estados Unidos. 


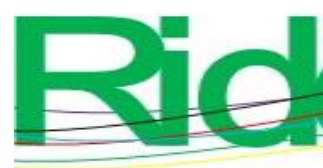

Tabla 2. Materias vinculadas al canto del mapa curricular de la licenciatura en Canto de la Universidad de Houston

\begin{tabular}{|c|c|c|c|c|c|c|c|c|}
\hline $\begin{array}{l}\text { Seme } \\
\text { stre }\end{array}$ & 1 & 2 & 3 & 4 & 5 & 6 & 7 & 8 \\
\hline $\begin{array}{l}\text { Crédi } \\
\text { tos }\end{array}$ & 10 & 10 & 10 & 13 & 10 & 8 & 11 & 7 \\
\hline $\begin{array}{l}\text { Mater } \\
\text { ia }\end{array}$ & $\begin{array}{l}\text { Leccion } \\
\text { es } \\
\text { aplicad } \\
\text { as } 1 \text { (3 } \\
\text { créd.) }\end{array}$ & $\begin{array}{l}\text { Leccion } \\
\text { es } \\
\text { aplicad } \\
\text { as } 2 \text { (3 } \\
\text { créd.) }\end{array}$ & $\begin{array}{l}\text { Leccion } \\
\text { es } \\
\text { aplicad } \\
\text { as } 3 \text { (3 } \\
\text { créd.) }\end{array}$ & $\begin{array}{l}\text { Leccion } \\
\text { es } \\
\text { aplicad } \\
\text { as } 4 \text { (3 } \\
\text { créd.) }\end{array}$ & $\begin{array}{l}\text { Leccion } \\
\text { es } \\
\text { aplicada } \\
\text { s } 5 \quad(3 \\
\text { créd.) }\end{array}$ & $\begin{array}{l}\text { Leccio } \\
\text { nes } \\
\text { aplicad } \\
\text { a } 6 \text { (3 } \\
\text { créd.) }\end{array}$ & $\begin{array}{l}\text { Leccione } \\
\mathrm{s} \\
\text { aplicadas } \\
7 \\
\text { créd.) }\end{array}$ & $\begin{array}{l}\text { Leccio } \\
\text { nes } \\
\text { aplicad } \\
\text { a } 8 \text { (3 } \\
\text { créd.) }\end{array}$ \\
\hline $\begin{array}{l}\text { Mater } \\
\text { ia }\end{array}$ & $\begin{array}{l}\text { Ensamb } \\
\text { les } 1 \text { (1 } \\
\text { créd.) }\end{array}$ & $\begin{array}{l}\text { Ensamb } \\
\text { les } 2 \text { (1 } \\
\text { créd.) }\end{array}$ & $\begin{array}{l}\text { Ensamb } \\
\text { les } 3 \text { (1 } \\
\text { créd.) }\end{array}$ & $\begin{array}{l}\text { Ensamb } \\
\text { les } 4 \text { (1 } \\
\text { créd.) }\end{array}$ & $\begin{array}{l}\text { Ensamb } \\
\text { les } 5 \text { (1 } \\
\text { créd.) }\end{array}$ & $\begin{array}{l}\text { Ensam } \\
\text { bles } 6 \\
(1 \\
\text { créd.) }\end{array}$ & $\begin{array}{l}\text { Ensambl } \\
\text { es } 7 \text { (1 } \\
\text { créd.) }\end{array}$ & $\begin{array}{l}\text { Ensam } \\
\text { bles } 8 \\
(1 \\
\text { créd.) }\end{array}$ \\
\hline $\begin{array}{l}\text { Mater } \\
\text { ia }\end{array}$ & $\begin{array}{l}\text { Dicción } \\
\text { vocal } 1 \\
\text { (1 } \\
\text { créd.) }\end{array}$ & $\begin{array}{l}\text { Dicción } \\
\text { vocal } 2 \\
\text { (1 } \\
\text { créd.) }\end{array}$ & $\begin{array}{l}\text { Idioma } \\
\text { extranje } \\
\text { ro } 1 \text { (1 } \\
\text { créd.) }\end{array}$ & $\begin{array}{l}\text { Técnica } \\
\text { s de la } \\
\text { Música } \\
\text { del } \\
\text { siglo } \\
\text { XX (2 } \\
\text { créd.) }\end{array}$ & $\begin{array}{l}\text { Introduc } \\
\text { ción a } \\
\text { grandes } \\
\text { formas } \\
\text { musical } \\
\text { es (2 } \\
\text { créd.) }\end{array}$ & $\begin{array}{l}\text { Recital } \\
1\end{array}$ & $\begin{array}{l}\text { Literatur } \\
\text { a musical } \\
\text { avanzada } \\
1 \\
\text { créd.) }\end{array}$ & $\begin{array}{l}\text { Literat } \\
\text { ura } \\
\text { musica } \\
1 \\
\text { avanza } \\
\text { da } 2 \text { (3 } \\
\text { créd.) }\end{array}$ \\
\hline $\begin{array}{l}\text { Mater } \\
\text { ia }\end{array}$ & $\begin{array}{l}\text { Habilid } \\
\text { ades } \\
\text { auditiva } \\
\text { s } \quad 1 \quad \text { (1 } \\
\text { créd.) }\end{array}$ & $\begin{array}{l}\text { Habilid } \\
\text { ades } \\
\text { auditiva } \\
\text { s } 2 \text { (1 } \\
\text { créd.) }\end{array}$ & $\begin{array}{l}\text { Habilid } \\
\text { ades } \\
\text { auditiva } \\
\text { s } 3 \text { (1 } \\
\text { créd.) }\end{array}$ & $\begin{array}{l}\text { Habilid } \\
\text { ades } \\
\text { auditiva } \\
\text { s } 4 \text { (1 } \\
\text { créd.) }\end{array}$ & $\begin{array}{l}\text { Actuaci } \\
\text { ón para } \\
\text { Ópera (1 } \\
\text { créd.) }\end{array}$ & $\begin{array}{l}\text { Actuac } \\
\text { ión } \\
\text { para } \\
\text { Ópera } \\
\text { (1 } \\
\text { créd.) }\end{array}$ & $\begin{array}{l}\text { Conducc } \\
\text { ión de } \\
\text { Coros } 2 \\
\text { (2 créd.) }\end{array}$ & $\begin{array}{l}\text { Recital } \\
\text { final }\end{array}$ \\
\hline $\begin{array}{l}\text { Mater } \\
\text { ia }\end{array}$ & $\begin{array}{l}\text { Piano } \\
\text { grupal } 1 \\
\text { (1 } \\
\text { créd.) }\end{array}$ & $\begin{array}{l}\text { Piano } \\
\text { grupal } 2 \\
\text { (1 } \\
\text { créd.) }\end{array}$ & $\begin{array}{l}\text { Piano } \\
\text { grupal } 3 \\
\text { (1 } \\
\text { créd.) }\end{array}$ & $\begin{array}{l}\text { Piano } \\
\text { grupal } 4 \\
\text { (1 } \\
\text { créd.) }\end{array}$ & $\begin{array}{l}\text { Escritur } \\
\text { a } \\
\text { créd.) }\end{array}$ & $\begin{array}{l}\text { Polític } \\
\text { as de } \\
\text { Texas }\end{array}$ & $\begin{array}{l}\text { Pedagogí } \\
\text { a de la } \\
\text { Interpret }\end{array}$ & \\
\hline
\end{tabular}




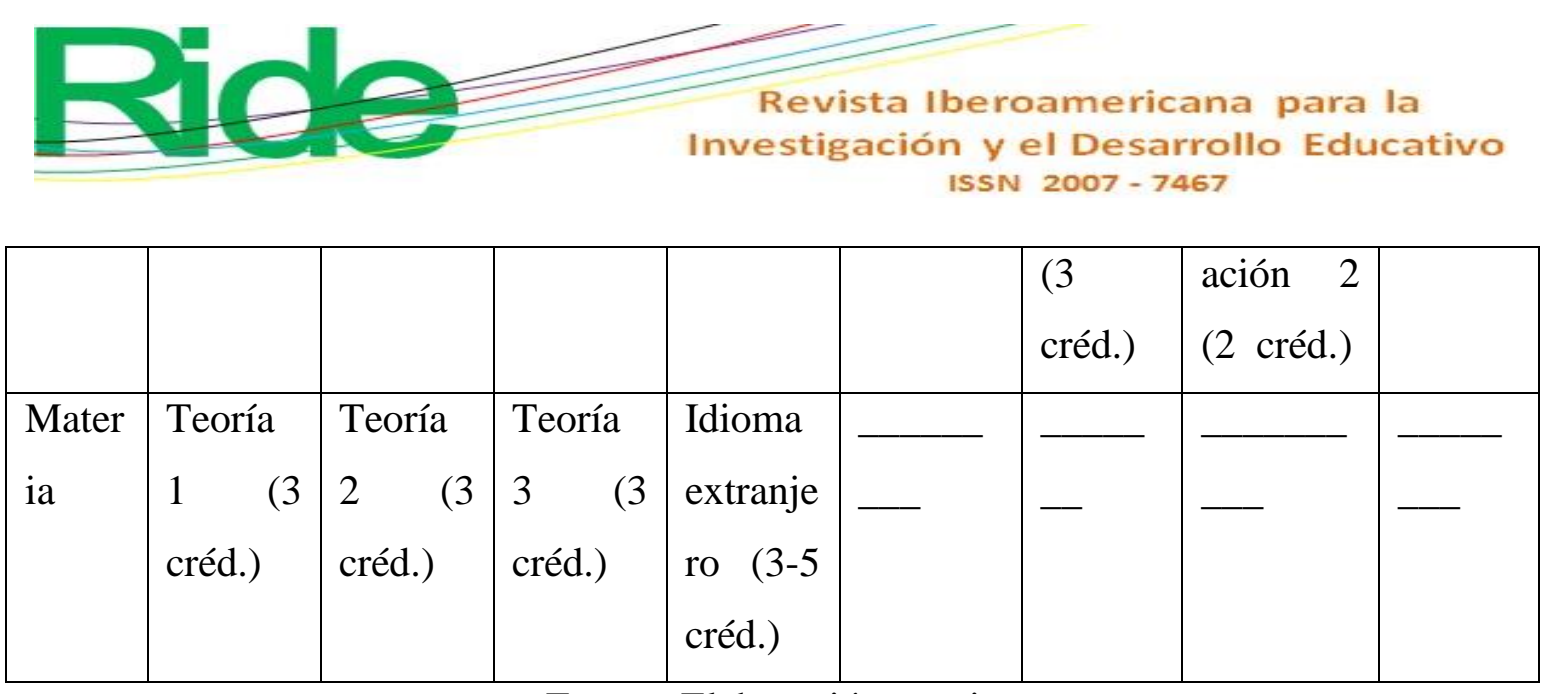

Fuente: Elaboración propia

Un punto interesante en esta tabla es la reducción de materias hacia el final de la carrera, dejando espacio al recital de titulación, elemento que también coincide con el mapa curricular de la licenciatura de Zacatecas. El mapa curricular de la licenciatura en Canto de la Universidad de Houston presenta opciones importantes como vinculación primaria: Actuación para Ópera y Pedagogía de la Interpretación. También la materia de conducción de coros abre una nueva orientación para la dirección coral. No se especifica el idioma italiano, pero aparece la materia de Dicción, lo cual determina su aplicación al canto. Las materias de Técnicas de la Música del siglo XX ofrecen un panorama aún más extenso para un perfil de egreso hacia la pertinencia de la profesión. Las materias de Solfeo y Entrenamiento Auditivo se encuentran presentes en los tres programas como materias de primer orden y aparecen bajo diferentes denominaciones.

Una carencia encontrada en los tres programas es la materia de Orientación Profesional. La figura del orientador profesional como primer contacto con la realidad social y laboral dentro de la carrera, se puede considerar imprescindible. Los aportes que ofrece la orientación profesional pueden ser varios, según Polanco (2013):

1) Porque facilita una información imprescindible al alumnado sobre la variedad de opciones profesionales que existen en el actual mercado laboral de la música, y sobre las funciones específicas que se requieren para cada caso; 2) porque aporta asesoramiento en la toma de decisiones durante todo el itinerario formativo; y 3) porque contribuye al éxito del proceso educativo (Polanco, 2013, párr. 2).

En la UAA-UAZ se ejercen las tutorías, programa que aún tiene mucho por ofrecer. Esta dirección tutorial debe desarrollarse a través de un conjunto de profesionales que puedan ejercer la orientación profesional.

El perfil de egreso de la licenciatura en Canto de la Universidad Autónoma de Zacatecas es el siguiente: el egresado será un profesional con una sólida educación integral 


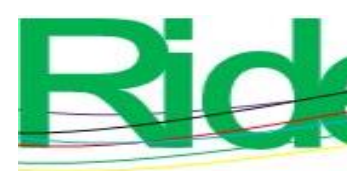

Revista Iberoamericana para la
Investigación y el Desarrollo Educativo
ISSN $2007-7467$

que le permita llegar a altos grados de flexibilidad, polivalencia, autonomía, creatividad y sentido crítico. Además, desarrollará un nivel de conciencia profundo acerca de sus posibilidades de desarrollo profesional, un amplio conocimiento acerca de la música, y un alto nivel de habilidades y conocimientos técnicos en su área de énfasis: educación, teoría y composición e interpretación. El licenciado en Canto poseerá un conjunto de valores, conocimientos y habilidades relacionados con los conocimientos específicos de la disciplina musical en sus aspectos teóricos y prácticos y un conjunto de habilidades y destrezas específicas a la práctica de la profesión en un marco de habilidades de autodesarrollo y valores, y un énfasis en la interpretación, educación, teoría y composición musical.

El alumno debe de desarrollar, entonces, un profundo nivel de conciencia acerca de sus posibilidades, lo cual no es posible si no se canaliza a través de la orientación profesional. En cuanto al conjunto de habilidades relacionadas con los conocimientos de la disciplina, se debe de partir desde cómo se produce el paradigma formativo de un cantante. En palabras de Seidner y Wendler (1982):

La aplicación provechosa de estos conocimientos en la enseñanza depende de la medida en que se tome en cuenta la individualidad del alumno y el grado de desarrollo de sus capacidades. Las posibilidades son muchas, y una enseñanza vocal exitosa presupone que se tomen igualmente en cuenta referencias individuales y sociales, que siempre sean incorporadas a las reflexiones metodológicas (Seidner y Wendler, 1982, p. 21).

Este paradigma tiene que ver con parámetros de versatilidad en cuanto a sus capacidades intrínsecas. Siendo la voz un instrumento sumamente complejo de formar, la individualidad del alumno debe de ser revisada con sumo cuidado por su docente. Por esta razón, las reflexiones metodológicas van en el sentido de la enseñanza personalizada. El docente de Canto, siguiendo la enseñanza conservatoriana, muestra a un excantante o cantante activo que comparte y practica una enseñanza basada en lo empírico, transfiriendo el contenido y uso de sus herramientas propias, hacia el estudiante. Se asume que sean músicos completos, pero paradójicamente la docencia deja poco espacio para un desarrollo como intérprete o concertista. Esto lo afirma Regelski y Lines (2009): “Así, pues, de los profesores de música se espera que, para poder enseñar, sean músicos, y los estudios musicales dejan poco espacio para su preparación como profesores” (p. 23). 


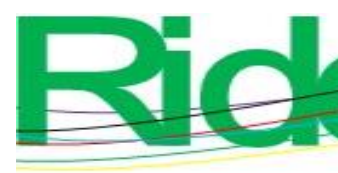

Revista Iberoamericana para la
Investigación y el Desarrollo Educativo
ISSN $2007-7467$

Las características a tomar en cuenta para acometer la docencia en el canto son varias e irrenunciables. Al respecto, opina el cantante y pedagogo vocal estadounidense Richard Miller (2004):

Hay ciertas preguntas que se deben de formular para reconocer la calidad de un docente: ¿la técnica va acorde a la función de la libertad y las leyes de la acústica vocal?, ¿son claros los objetivos de los patrones de vocalización?, ¿el maestro utiliza un lenguaje entendible y adecuado, evitando lo seudocientífico y lo mitológico? Escucha si la técnica y la interpretación están balanceadas, y determina si la lección produce resultados reconocibles. ¿Hay un sentido de la honestidad, falta de pomposidad, ausencia de solicitud empalagosa, evita conductas omnipotentes? ¿conoce las necesidades de los estudiantes? y, sobre todo, ¿la lección es alrededor del estudiante o alrededor del maestro? (Miller, 2004, p. 218).

El docente de canto debe de estar en constante actualización y preparación para poder acometer la difícil tarea de la formación vocal y llevar al alumno a un camino exitoso; pero, por otro lado, demanda una función desgastante y compleja al convertirse en hacedor y tutor del estudiante que debe de acometer lo propuesto en el perfil de egreso.

Por otra parte, se puede indicar que el proceso de evaluación es otro aspecto que debe ser revisado. Montoya (2017) subraya lo siguiente:

La evaluación constituye un recurso de aprendizaje para maestros y alumnos. En nuestro caso para revisar posibles deficiencias en la enseñanza, falta de correlación entre los objetivos planteados con el desarrollo de las actividades para alcanzarlos (...), y lo más importante: la evaluación debe ayudar a los estudiantes a mejorar su desempeño académico, a fin de disminuir la brecha entre su rendimiento presente y el requerido (Montoya, 2017, p. 273).

En otras palabras, las evaluaciones no son el fin de un camino semestral o anual, sino un medio para potenciar el aprendizaje del estudiante.

Aunado a esto el sistema universitario se comporta como un sistema empresarial en donde el conteo de las horas trabajadas pesa más que la calidad en el trabajo. Esto trae como resultado una sobrecarga de alumnos que termina por extenuar al docente y exponer el cumplimiento laboral por encima de la calidad educativa. Gutiérrez (1984) afirma que la actividad del docente está supeditada a lo mecánico del programa y al sometimiento de la entrega de calificaciones, lo que provoca relaciones monótonas y antieducativas.

Vol. 12, Núm. 22 Enero - Junio 2021, e250 


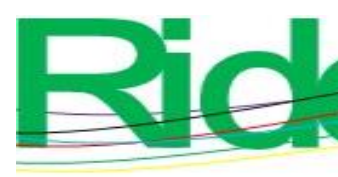

Revista Iberoamericana para la
Investigación y el Desarrollo Educativo
ISSN $2007-7467$

El papel del alumno también es fundamental, por lo que se prefiere una enseñanza de índole constructivista. Generalmente, los estudiantes de canto llegan a clases con ideas preconcebidas. Sin embargo, según Fleming (2004), "la labor del estudiante es tener la mente abierta” (p. 54), pero se cierran a la enseñanza. El trabajo en este sentido debe de ser recíproco, o sea, una tarea combinada en donde el alumno se muestra maleable y capaz de depositar la confianza en su maestro.

Bajo este análisis se consideró importante tomar como base el análisis FODA con el objetivo de ofrecer un claro diagnóstico que coadyuve a una mejor visualización de la situación actual.

\section{Panorama laboral}

En México, las áreas en donde el campo laboral suele tener una mayor perspectiva no tienen relación con lo artístico. De hecho, el trabajo artístico suele ser intermitente y bajo en ingresos, por lo que muchas veces no es viable financieramente. Por ello, es necesario conocer el fluctuante mercado laboral. Suele darse la comunicación entre empleadores y estudiantes, lo que debería ya convertirse en una práctica común, pues los que emplean demandan habilidades, actitudes y aptitudes de los egresados. En palabras de Lara (2016), "sería también interesante que nos preguntasen a los empleadores qué se necesita para ejercer determinadas profesiones dentro del ámbito musical “(p. 115). Los empleadores en el ámbito del canto lírico en México son escasos. Un cantante lírico tiene como perspectiva trasladarse a otros países, especialmente al continente europeo como opción principal para desarrollar su carrera.

En este panorama, en México, el Teatro Nacional de Bellas Artes es el único que tiene temporadas operísticas en todo el país. El resto son algunas compañías autosustentables y ensambles vocales que no laboran de manera regular, con un presupuesto muy variable e inestable.

La ópera es un género que en la actualidad se ha mostrado decadente, como lo señala Mortier (2010):

Lo que es en cambio cierto es que la disminución de la nueva creación, así como su rechazo por una gran parte del público pretendidamente aficionado a la ópera, y la repetición permanente de las mismas obras en diferentes puestas en escena deben necesariamente llevar a la decadencia del propio género y 


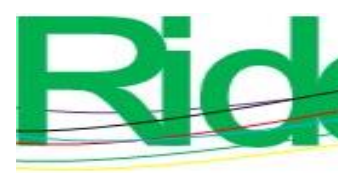

Revista Iberoamericana para la Investigación y el Desarrollo Educativo ISSN 2007-7467

acabarán generando una pérdida de interés por parte de un nuevo público (Mortier, 2010, p. 78).

La profesión de cantante de ópera ya no es en la actualidad una opción laboral satisfactoria. De hecho, la ópera como género - en especial, en las actuales circunstanciasno tiene la misma pertinencia que hace décadas. Por siglos ha sido una de las más importantes expresiones artísticas, pero actualmente ha quedado descontextualizada. Su desconexión con la actual búsqueda de identidad es muy evidente:

La única manera de seguir haciendo ópera es resignificándola. Tiene que comunicar algo que tenga significado en esta época; debe tocar alguna fibra que resulte cercana. Creo en el poder de la ópera como género, pero ese poder debe ser puesto en discusión cada vez (Grimoldi, 2016, párr. 24).

Asimismo, Carlos López (2017) destaca la aparición de nuevas óperas:

El elitismo es el mayor problema que hoy tiene la ópera (...). Avanza poco a poco la idea de crear óperas nuevas de menor formato, a una escala que haga el espectáculo más económico. De la misma forma, la ópera debería reinventarse con nuevos títulos, nuevos compositores y por supuesto, muchos nuevos aficionados (López, 2017, párr. 9).

Las nuevas óperas están surgiendo desde hace décadas. Según Morgades (6 de octubre de 2006), aparecen óperas nuevas de todos los formatos, grandes producciones de cámara o de bolsillo, y de estilos musicales muy diversos en una época, la actual, de absoluta libertad estética. Óperas que están cimentando lo que será el repertorio lírico del siglo XXI.

Aun así, la ópera no alcanza el éxito que tiene, por ejemplo, el cine, que resulta por demás seductor. Para López (2017) en los años 30, con la aparición del cine a color, la ópera perdió aficionados que luego se fueron intelectualizando. Por ende, no hay un destello real de resurgimiento operístico dejando a los actuales egresados de la carrera de cantante en desventaja con respecto a otras profesiones mucho más necesarias y pertinentes.

En el mundo de la música popular, las condiciones dependen de la mercadotecnia. Los músicos en general pueden conformar sus diferentes agrupaciones, siendo la parte más difícil la permanencia y la estabilidad laboral debido a la competencia y al fluctuante gusto del público, lo que ha provocado que productores tomen decisiones cambiantes que afectan el trabajo del artista. Con la relevancia de portales como Youtube o Spotify los cantantes de todos los estilos están abriendo nuevos caminos para su promoción, pero el desarrollo de 


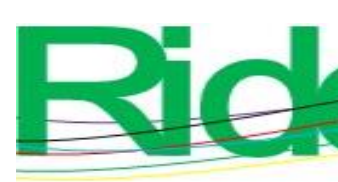

Revista Iberoamericana para la Investigación y el Desarrollo Educativo ISSN $2007-7467$

contenido no es una fuente estable de entrada económica, o todavía no lo es. Al respecto, Pardo (2011) señala lo siguiente:

En la producción artística no ocurre como en otras ramas creativas, que están reconocidas como profesiones y cuya remuneración no es puesta en duda, sino que es la consecuencia lógica de un trabajo realizado: arquitectos, publicistas, diseñadores industriales o gráficos (...) son ocupaciones legitimadas como tales (Pardo, 2011, párr. 4).

En el caso particular del estado de Zacatecas, en donde hay un mundo musical más o menos activo, la situación no es alentadora para los cantantes. En entrevistas con diferentes docentes y cantantes de Zacatecas y estados aledaños, manifestaron que los grupos operísticos líricos o de corte popular en el estado de Zacatecas dependen de proyectos aceptados por las instituciones culturales que generalmente caen en una especie de regateo por los proyectos ofrecidos, por lo que los trabajos de cantantes locales suelen ser esporádicos y generalmente mal pagados. Debido a esto, la mayoría se ven forzados a buscar otros empleos fuera del ámbito artístico mientras esperan la siguiente oportunidad para poder ejercer como cantantes profesionales.

Acorde a la encuesta realizada para esta investigación, las políticas culturales no alientan la estabilidad del empleo en los cantantes. A pesar de existir convocatorias que promueven el quehacer del cantante en el estado, son insuficientes, temporales y selectivas. La mayoría de los cantantes no pueden establecerse como tal a través de un empleo digno que les permita ejercer la profesión estudiada.

\section{Metodología}

Esta fue una investigación mixta (cualitativa-cuantitativa), de tipo exploratorio con investigación documental y de campo, con una muestra no probabilística obtenida por consenso de los 31 participantes.

La primera fase fue de corte cualitativo, pues se exploró el caso estudiado a través de la perspectiva general desde diferentes ángulos, por medio de lo histórico y lo académico. Esto apoyado en la siguiente pregunta de investigación: ¿cuáles son las relaciones entre la desconexión del perfil de egreso y la inserción al mercado laboral?

La segunda fase fue de corte cuantitativo, pues se concretó mediante diferentes elementos que miden parámetros de calidad y cantidad. 


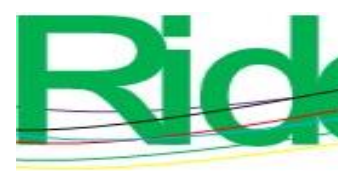

Revista Iberoamericana para la
Investigación y el Desarrollo Educativo
ISSN $2007-7467$

La investigación documental fue realizada con el análisis del programa actual de la licenciatura a través de la exposición de ciertas materias carentes y otras que no están vinculadas al canto y el perfil del egresado de acuerdo con lo establecido en el programa de la carrera.

La investigación de campo se desarrolló a través de una encuesta a 31 cantantes de diferentes condiciones: 15 estudiantes, 6 docentes y 10 cantantes profesionales, para tener un sondeo de la vinculación del programa actual de la licenciatura en Canto y los nuevos perfiles laborales. De este modo se precisaron las fortalezas y debilidades del sistema académico en el área de canto de la UAA-UAZ. Así se consiguió un diagnóstico y pronóstico del egresado en la inclusión al mercado laboral.

\section{Procedimiento}

- Realización de la investigación documental revisando el programa actual de la licenciatura en Canto, así como ciertos documentos oficiales sobre los reconocimientos y acreditaciones.

- Colaboración de la actual administración (2016-2020) con el envío del mapa curricular de la licenciatura en Canto.

- Realización de la investigación de campo mediante una encuesta realizada con una muestra de 31 cantantes con condiciones diferentes: docentes, estudiantes y cantantes profesionales.

Consideraciones para la aplicación de la encuesta:

- La encuesta estuvo dirigida a tres grupos de cantantes en diferentes estados académicos o laborales: estudiantes, docentes y cantantes profesionales en activo, y medida con escala de Likert, método que utilizan investigadores para evaluar la opinión y las aptitudes de las personas.

Esta encuesta se confeccionó con preguntas analizadas desde la perspectiva de la pregunta de investigación, sin condiciones previas. 


\section{Resultados}

En la Encuesta Nacional de Ocupación y Empleo (ENOE) se determinó que para el primer trimestre del año 2020, $79 \%$ de los profesionistas del país trabajaban de manera subordinada y remunerada. De hecho, los profesionales del área de artes representan el porcentaje más bajo empleado, según el Observatorio Laboral (OLA), como se muestra en la tabla 3 .

Tabla 3. Carreras que poseen los porcentajes más elevados de trabajadores por cuenta propia

\begin{tabular}{|l|l|}
\hline $\begin{array}{l}\text { Carreras de trabajadores por cuenta } \\
\text { propia }\end{array}$ & Porcentaje \\
\hline Estomatología y odontología & 43.4 \\
\hline Bellas artes & 33.4 \\
\hline Veterinaria & 33.9 \\
\hline
\end{tabular}

Fuente: Página oficial del Observatorio Laboral del Gobierno de México

La pertinencia de la profesión como cantantes profesionales exige una inmediata revaloración, pues no es una labor susceptible de financiamiento en México. Paradójicamente, la licenciatura en Canto de la Unidad de Artes sigue recibiendo aspirantes cada semestre que elaboran proyectos y creaciones por demás interesantes.

Para tener un panorama más claro en cuanto a las ventajas y desventajas que podría traer el estudio de una licenciatura de esta naturaleza, se realizó un análisis FODA, cuyos resultados fueron los siguientes:

\section{Análisis FODA}

Fortalezas

- La licenciatura en Canto es una carrera oficial que ofrece una opción de titulación en el centro del país.

- La planta docente es de calidad, con maestros nacionales y extranjeros de formación muy profesional.

- Los costos para estudiar una licenciatura en Canto en la UAZ son realmente accesibles para los jóvenes aspirantes. 


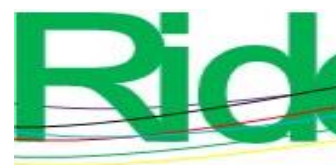

Revista Iberoamericana para la
Investigación y el Desarrollo Educativo
ISSN $2007-7467$

- La licenciatura ofrece un programa para una formación integral del estudiante con un plan de estudios actualmente en reestructuración, cuyo objetivo es mantener una carrera organizada acorde a los indicadores que exige la universidad.

- El programa de tutorías crece continuamente con las necesidades académicas.

- La UAZ tiene una posición geográfica estratégica que beneficia a los estudiantes de estados aledaños para cursar la licenciatura.

\section{Debilidades}

- No existen salidas como cantante popular, cantante de coro, director de coros, docente o investigador en el área del canto.

- $\quad$ El plan de estudios de la licenciatura necesita más materias vinculadas al canto.

- Carece de una asignatura de orientación profesional.

- El programa debe reestructurarse de acuerdo con la actual realidad estatal.

- El perfil de egreso requiere reestructuración.

Oportunidades

- La ciudad de Zacatecas, patrimonio de la humanidad y capital de la cultura, es un lugar perfecto para crear diferentes oportunidades para los cantantes del estado.

- Hay suficiente material vocal para formar proyectos serios y duraderos.

- Debido a la posición geográfica del estado, se pueden organizar convenios de colaboración con estudiantes y músicos de los estados aledaños.

- Los cambios tecnológicos y el uso de las TIC están ofreciendo nuevas alternativas para proyectos emergentes dentro del área del canto en Zacatecas y en el resto del país.

- Debido a la cercanía, los estudiantes y docentes pueden formar redes de información e investigación para elaborar proyectos que propongan modificaciones dentro de las políticas culturales.

- Debido a esta misma posición geográfica, se pueden realizar talleres de capacitación que desemboquen en proyectos artísticos con bases sólidas que concluyan en el empleo de los cantantes, profesionales y egresados del estado.

\section{Amenazas}

- La desvinculación con el actual y limitado panorama laboral perjudica el quehacer artístico de los egresados y docentes en el área del canto.

- La poca importancia que tiene el arte y la música desde los niveles básicos y hasta dentro de los hogares no fortalece un ambiente cultural. 


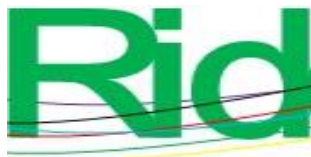

Revista Iberoamericana para la
Investigación y el Desarrollo Educativo
ISSN $2007-7467$

- Las políticas culturales no promueven la estabilidad laboral de los cantantes del estado.

- No hay estrategias laborales para la inserción en un mercado reducido.

También se realizó el vaciado de respuestas de la encuesta aplicada. Las terminaciones empleadas corresponden a $\mathrm{E}$ (estudiante), D (docente) y CP (cantante profesional). 


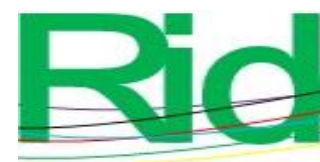

Revista Iberoamericana para la Investigación y el Desarrollo Educativo ISSN 2007 - 7467

Tabla 4. Resultados de la encuesta

\begin{tabular}{|c|c|c|c|c|c|}
\hline Preguntas & $\begin{array}{l}\text { Totalmente } \\
\text { de acuerdo }\end{array}$ & $\begin{array}{l}\text { En } \\
\text { desacuerdo }\end{array}$ & Neutral & De acuerdo & $\begin{array}{l}\text { Totalmente } \\
\text { de acuerdo }\end{array}$ \\
\hline $\begin{array}{l}\text { ¿Consideras } \\
\text { posible que un } \\
\text { cantante pueda } \\
\text { formarse con alto } \\
\text { nivel dentro de } \\
\text { las instituciones } \\
\text { nacionales que } \\
\text { ofrecen carreras } \\
\text { artísticas? }\end{array}$ & & $2 \mathrm{D}$ & $\begin{array}{l}3 \mathrm{E}, 2 \mathrm{D}, \\
3 \mathrm{CP}\end{array}$ & $\begin{array}{l}7 \mathrm{E}, 2 \mathrm{D}, \\
4 \mathrm{CP}\end{array}$ & $5 \mathrm{E}, 3 \mathrm{CP}$ \\
\hline $\begin{array}{l}\text { ¿Crees que el } \\
\text { programa de } \\
\text { estudios de la } \\
\text { licenciatura en } \\
\text { Canto de la UAZ } \\
\text { está diseñado } \\
\text { para adquirir un } \\
\text { buen perfil de } \\
\text { egreso como } \\
\text { cantante } \\
\text { profesional? }\end{array}$ & $6 \mathrm{E}$ & $\begin{array}{l}3 \mathrm{E}, 3 \mathrm{D}, \\
5 \mathrm{CP}\end{array}$ & $3 \mathrm{CP}$ & $\begin{array}{l}6 \mathrm{E}, 2 \mathrm{D}, \\
2 \mathrm{CP}\end{array}$ & 1D \\
\hline $\begin{array}{l}\text { ¿Crees que el } \\
\text { exceso de } \\
\text { asignaturas } \\
\text { teóricas en el } \\
\text { programa de } \\
\text { licenciatura en } \\
\text { Canto de la UAZ } \\
\text { es una causante } \\
\text { para la deserción } \\
\text { de los } \\
\text { estudiantes? }\end{array}$ & & $1 \mathrm{E}, 7 \mathrm{CP}$ & $1 \mathrm{E}, 3 \mathrm{CP}$ & 13E, 5D & 1D \\
\hline $\begin{array}{l}\text { ¿Crees que la } \\
\text { desconexión que } \\
\text { existe entre } \\
\text { asignaturas } \\
\text { teóricas y } \\
\text { prácticas sea un } \\
\text { problema para } \\
\text { lograr un buen } \\
\text { perfil de egreso? }\end{array}$ & & & $2 \mathrm{E}, 1 \mathrm{CP}$ & $5 \mathrm{D}$ & $\begin{array}{l}13 \mathrm{E}, 1 \mathrm{D}, \\
9 \mathrm{CP}\end{array}$ \\
\hline $\begin{array}{l}\text { ¿Consideras que } \\
\text { los idiomas que } \\
\text { se imparten no se } \\
\text { llevan a cabo }\end{array}$ & & & $1 \mathrm{CP}$ & $9 \mathrm{CP}$ & $15 \mathrm{E}, 6 \mathrm{D}$ \\
\hline
\end{tabular}




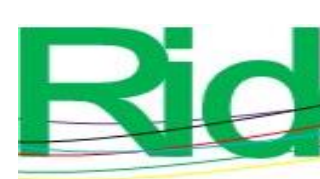

Revista Iberoamericana para la Investigación y el Desarrollo Educativo ISSN 2007 - 7467

\begin{tabular}{|c|c|c|c|c|c|}
\hline $\begin{array}{l}\text { como debe de } \\
\text { ser? }\end{array}$ & & & & & \\
\hline $\begin{array}{l}\text { ¿Consideras que } \\
\text { la materia de } \\
\text { Piano Funcional } \\
\text { que se imparte en } \\
\text { la Unidad de } \\
\text { Artes de la UAZ } \\
\text { pudiera ser una } \\
\text { mejor } \\
\text { herramienta para } \\
\text { los cantantes? }\end{array}$ & & $1 \mathrm{CP}$ & $2 \mathrm{E}, 4 \mathrm{CP}$ & $13 \mathrm{E}$ & $6 \mathrm{D}, 5 \mathrm{CP}$ \\
\hline $\begin{array}{l}\text { ¿Consideras que } \\
\text { el perfil de egreso } \\
\text { de la licenciatura } \\
\text { en Canto de la } \\
\text { UAZ cumple los } \\
\text { requisitos para } \\
\text { insertarse en el } \\
\text { mercado laboral? }\end{array}$ & $1 \mathrm{CP}$ & $4 \mathrm{E}, 7 \mathrm{CP}$ & $\begin{array}{l}5 \mathrm{E}, 2 \mathrm{D}, \\
2 \mathrm{CP}\end{array}$ & $6 \mathrm{E}, 2 \mathrm{D}$ & $2 \mathrm{D}$ \\
\hline $\begin{array}{l}\text { ¿Consideras } \\
\text { necesario tener un } \\
\text { título de } \\
\text { licenciado en } \\
\text { Canto para } \\
\text { ejercer la } \\
\text { profesión? }\end{array}$ & $6 \mathrm{CP}$ & $\begin{array}{l}3 \mathrm{E}, 1 \mathrm{D}, \\
3 \mathrm{CP}\end{array}$ & $5 \mathrm{E}, 1 \mathrm{D}$ & $\begin{array}{l}4 \mathrm{E}, 4 \mathrm{D}, \\
1 \mathrm{CP}\end{array}$ & $3 \mathrm{E}$ \\
\hline $\begin{array}{l}\text { ¿Consideras que } \\
\text { las políticas } \\
\text { culturales del } \\
\text { estado de } \\
\text { Zacatecas } \\
\text { favorecen el } \\
\text { quehacer del } \\
\text { cantante } \\
\text { profesional? }\end{array}$ & $\begin{array}{l}7 \mathrm{E}, 6 \mathrm{D}, \\
8 \mathrm{CP}\end{array}$ & $6 \mathrm{E}$ & $2 \mathrm{CP}$ & $2 \mathrm{E}$ & \\
\hline $\begin{array}{l}\text { ¿Consideras que } \\
\text { se necesita } \\
\text { desarrollar más } \\
\text { competencias } \\
\text { profesionalizantes } \\
\text { dentro de la } \\
\text { licenciatura en } \\
\text { Canto de la } \\
\text { UAZ? }\end{array}$ & & & & $2 \mathrm{E}, 1 \mathrm{D}$ & $\begin{array}{l}13 \mathrm{E}, 5 \mathrm{D}, \\
10 \mathrm{CP}\end{array}$ \\
\hline $\begin{array}{l}\text { ¿Consideras que } \\
\text { es importante la } \\
\text { inserción de }\end{array}$ & & & $1 \mathrm{CP}$ & $7 \mathrm{E}, 7 \mathrm{CP}$ & $8 \mathrm{E}, 6 \mathrm{D}, 2 \mathrm{CP}$ \\
\hline
\end{tabular}




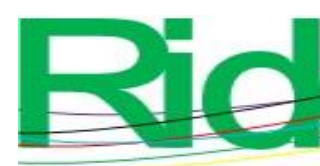

\begin{tabular}{|c|c|c|c|c|c|}
\hline $\begin{array}{l}\text { alguna materia } \\
\text { referente a la } \\
\text { orientación } \\
\text { profesional } \\
\text { dentro de la } \\
\text { licenciatura en } \\
\text { Canto de la } \\
\text { UAZ? }\end{array}$ & & & & & \\
\hline $\begin{array}{l}\text { ¿Preferirías } \\
\text { prepararte como } \\
\text { cantante en } \\
\text { cursos } \\
\text { particulares y no } \\
\text { en una } \\
\text { institución? }\end{array}$ & $6 \mathrm{E}, 4 \mathrm{CP}$ & $6 \mathrm{D}$ & $4 \mathrm{E}, 1 \mathrm{CP}$ & $5 \mathrm{E}, 5 \mathrm{CP}$ & \\
\hline $\begin{array}{l}\text { ¿Consideras que } \\
\text { ser cantante de } \\
\text { ópera es una } \\
\text { profesión } \\
\text { redituable? }\end{array}$ & $3 \mathrm{D}$ & $\begin{array}{l}4 \mathrm{E}, 1 \mathrm{D}, \\
6 \mathrm{CP}\end{array}$ & $\begin{array}{l}5 \mathrm{E}, \\
2 \mathrm{D}, 2 \mathrm{CP}\end{array}$ & $6 \mathrm{E}$ & $2 \mathrm{CP}$ \\
\hline $\begin{array}{l}\text { ¿Consideras que } \\
\text { es más redituable } \\
\text { ser cantante de } \\
\text { corte popular que } \\
\text { cantante lírico? }\end{array}$ & $1 \mathrm{D}$ & $\begin{array}{l}6 \mathrm{E}, 4 \mathrm{D}, \\
5 \mathrm{CP}\end{array}$ & $5 \mathrm{E}$ & $1 \mathrm{D}, 5 \mathrm{CP}$ & $4 \mathrm{E}$ \\
\hline $\begin{array}{l}\text { ¿Consideras } \\
\text { importante que se } \\
\text { abra una } \\
\text { licenciatura en } \\
\text { Canto Popular en } \\
\text { la Unidad de } \\
\text { Artes de la UAZ? }\end{array}$ & & & $\begin{array}{l}5 \mathrm{E}, 6 \mathrm{D}, \\
4 \mathrm{CP}\end{array}$ & $5 \mathrm{E}$ & $5 \mathrm{E}, 6 \mathrm{CP}$ \\
\hline
\end{tabular}

Fuente: Elaboración propia

Asimismo, en la figura 2 observamos que los profesionistas del arte ocupados en el año 2020 representan un bajo porcentaje en comparación con el resto de los profesionales. 

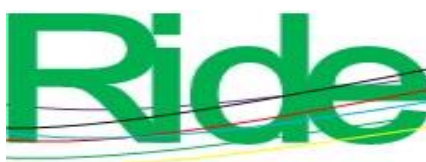

Revista Iberoamericana para la Investigación y el Desarrollo Educativo ISSN 2007 - 7467

Figura 2. Porcentaje de profesionistas ocupados por área de conocimiento

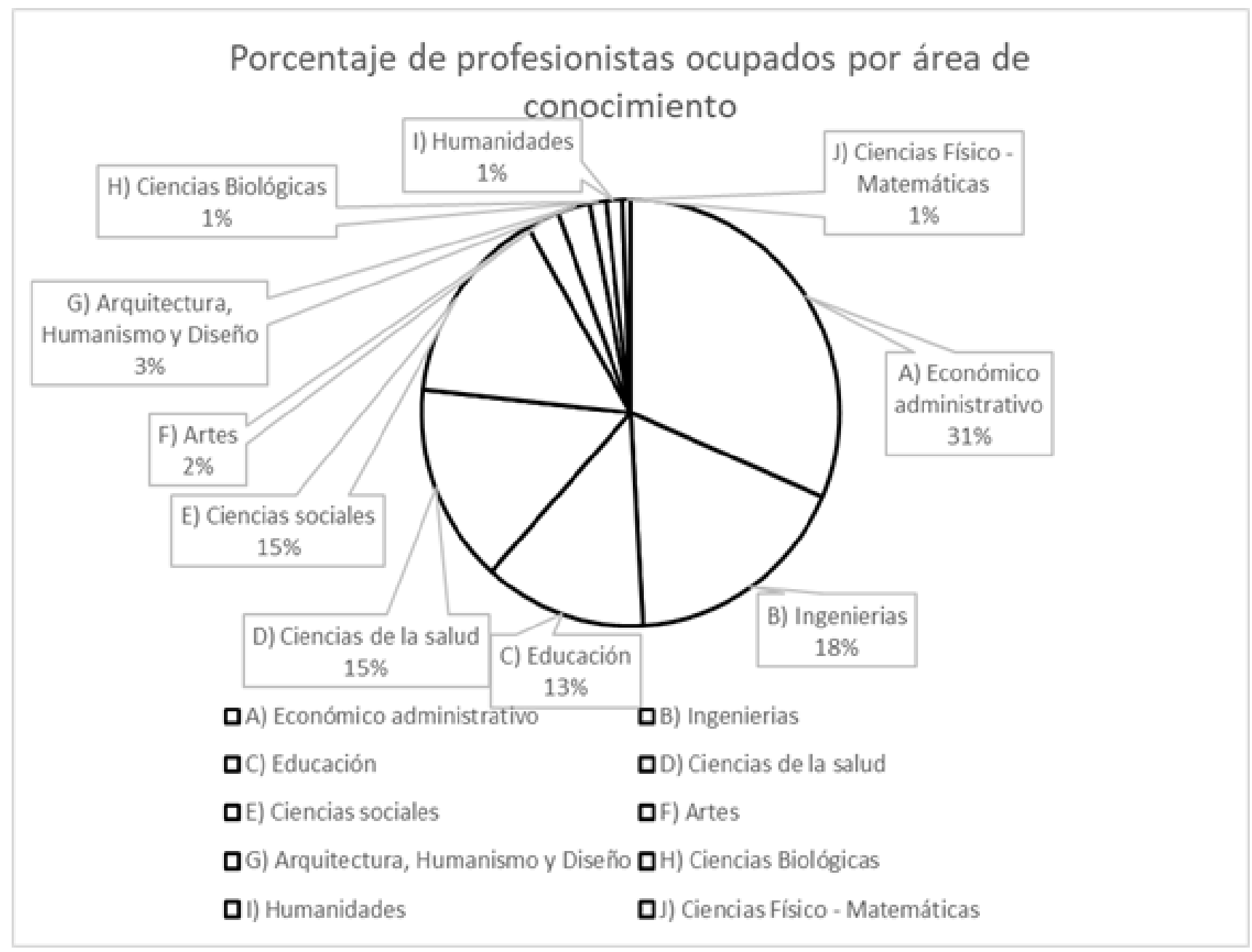

Fuente: Observatorio Laboral del Gobierno de México

\section{Discusión}

México, país en pleno desarrollo, se polariza muchas veces hacia lo financiero, de ahí que se incline preferentemente por profesionales en los campos que tengan directa relación con el crecimiento económico, lo que hace que el arte como profesión no tenga un campo laboral sustancioso. Por ello, los cantantes de México se encuentran entre los porcentajes bajos de empleados, lo que provoca que muchos busquen un trabajo fuera de su área de conocimiento. 


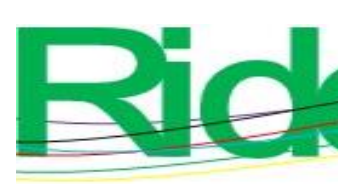

Revista Iberoamericana para la
Investigación y el Desarrollo Educativo
ISSN $2007-7467$

El programa de la licenciatura en Canto de la Universidad Autónoma de Zacatecas es un programa que se ha ido reestructurando con el paso de los diferentes ciclos escolares y que aún debe seguirse adecuando a la caótica situación social, sanitaria y financiera del país.

La desconexión entre lo que se estudia dentro de la licenciatura y lo que el mercado laboral demanda está vigente en la actualidad, por lo que se requieren materias inclusivas, como ensambles, música de cámara y otras que pueden redireccionar el énfasis terminal. En este sentido, la docencia debería ser uno de los énfasis dentro de esta licenciatura, pero esto representaría una interesante paradoja, pues la tendencia es que para convertirse en un relevante maestro de canto, es necesaria una gran experiencia previa como cantante sobre los diferentes escenarios, ya sean nacionales o internacionales.

Por ello, a nivel académico se han propuesto varias vertientes que pudieran comenzar a vincular la carrera del canto con la realidad social-laboral.

- La figura del orientador profesional en la licenciatura como punto de partida para la vinculación con el inestable mercado laboral.

- Un sistema de evaluación más flexible y pertinente que aporte fortalezas a las habilidades existentes de la academia y de los alumnos de canto.

- La reestructuración curricular continua, así como la inserción de materias de conexión al mercado laboral.

- La importancia del aprendizaje constructivista en las aulas de canto que promuevan la proactividad de los alumnos.

- La introducción de otros perfiles profesionales dentro del programa de canto, tales como cantante de coro, cantante de música popular (con sus diferentes estilos), docente, investigador del área, etc.

Por otra parte, vale comentar que esta investigación estuvo limitada por la misma irregularidad de las circunstancias actuales sociales y laborales, y por las continuas regulaciones de los parámetros educativos de la institución. Aun así, en esta investigación se ha procurado abrir el análisis sobre las relaciones entre la oferta curricular de la licenciatura y la inserción al mercado laboral, lo cual debe ser examinado en posteriores trabajos desde otros ángulos para generar diversas interpretaciones. 


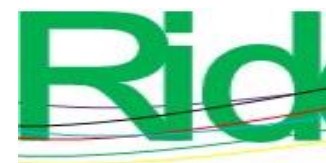

Revista Iberoamericana para la Investigación y el Desarrollo Educativo ISSN $2007-7467$

\section{Conclusiones}

Desde el punto de vista del mercado laboral, los cantantes se han visto y se siguen viendo afectados, pues una vez egresados de la licenciatura se encuentran con un panorama desconocido y hostil. La licenciatura es influenciada por los cambios sociales y culturales del estado y del contexto cultural que la rodea, lo que invita a asumir desde una nueva perspectiva la tarea del estudiante y del docente en cada ciclo escolar. En pocas palabras, la desvinculación entre las propias materias del plan de estudio es un hecho que influye en el perfil de egreso de los profesionales. En este contexto, las tutorías que se ejercen en la universidad se deben de desarrollar para acercarse a la tarea de la orientación profesional.

Por otra parte, cabe destacar que las políticas culturales deberían ser reforzadas con un lado más estratégico y humanístico para entender las necesidades culturales tanto de la audiencia como de los músicos y cantantes que necesitan ejercer su profesión sobre un escenario para poder vivir de ello, lo cual es un derecho humano de todo trabajador.

Sin embargo, los egresados de la licenciatura en Canto también deben ser conscientes y capaces de generar proyectos innovadores a través de la gestión y la correcta articulación, así como adquirir diferentes habilidades para entender la fenomenología de la ópera y del canto en el siglo XXI. En pocas palabras, los egresados de la licenciatura en Canto deben de reinventarse, revalorarse y buscar nuevas maniobras para poder mantenerse dentro de su profesión.

\section{Líneas de investigación}

Se debe profundizar en la reestructuración del programa analizado, el cual se ha visto afectado por políticas académicas y educativas que pueden ser remozadas con el fin de establecer una mayor coherencia entre el perfil de egreso de estos profesionales y el mercado laboral actual. 


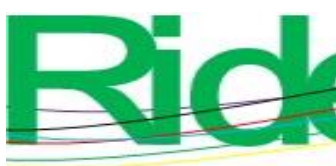

Revista Iberoamericana para la Investigación y el Desarrollo Educativo ISSN $2007-7467$

\section{Referencias}

Benzecry C. (2012). El fanático de la ópera: etnografía de una obsesión. Argentina: Siglo XXI.

Fleming, R. (2004). The inner voice, the making of a singer. New York: Penguin group.

Grimoldi, M. (2016). Marcelo Lombardero. Proyectos y visión de la ópera hoy. Entrevista con Marcelo Lombardero. Reflexión Académica en Diseño y Comunicación, 28, 146148.

Gutiérrez, F. (1984). Educación como praxis política. México: Siglo XXI.

Hernández, M del R. (26 de octubre 2020). Para la historia del ISA... La impronta de Ninón Lima. CIDMUC. Recuperado de https://cidmucmusicacubana.wordpress.com/2020/10/26/para-la-historia-del-isa-laimpronta-de-ninon-lima

Lara, L. (2016). ¿Pedagogía de qué? Artseduca, (13), 114-119. Recuperado de https://www.e-revistes.uji.es/index.php/artseduca/article/view/2051/1730

López, C. (2017). Salvemos la ópera. ¿Por qué Verdi y Wagner son un peligro para la ópera del futuro? Opera World. Recuperado de https://www.operaworld.es/salvemos-laopera-verdi-wagner-peligro-la-opera-del-futuro/

Miller, R. (2004). Solutions for singers. Tools performers and teachers. Oxford University Press. New York.

Montoya, L. M. (2017). Ser maestro hoy. México: Producciones Educación Aplicada.

Morgades, L. (6 de octubre de 2006). Ópera para el siglo XX. El País. Recuperado de https://www.elpais.com/diario/2006/10/07/babelia/1160175982_850215.html

Mortier, G. (2010). Dramaturgia de una pasión. Madrid: Akal.

Observatorio Laboral [OLA] (2020). Porcentaje de profesionistas ocupados por área de conocimiento. Recuperado de http://www.observatoriolaboral.gob.mx/static/estudiospublicaciones/Ola_indice_est adisticas_area.html

Pardo, S. (2011). De emergentes a sumergidos, nuevos artistas y mercado del arte. Arte y Sociedad, Recuperado

de httpps://dialnet.unirioja.es/servlet/articulo?codigo $=3792132$ 


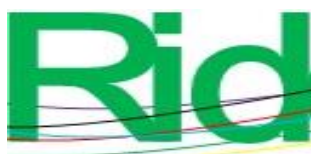

Revista Iberoamericana para la
Investigación y el Desarrollo Educativo
ISSN $2007-7467$

Polanco, R. (2013). La orientación académica y profesional en los Conservatorios de Música. Artseduca.

(5).

Recuperado

de https://dialnet.unirioja.es/servlet/articulo?codigo=4339753

Porras, I. (1 de octubre de 2019). Zacatecas será la capital americana de la cultura 2021. El Universal. Recuperado de https://www.eluniversal.com.mx/destinos/zacatecas-serala-capital-americana-de-la-cultura-2021

Regelski, T. y Lines, D. (coords.) (2009). La música y la educación musical: teoría y práctica para "marcar una diferencia”. La educación musical para el nuevo milenio: el futuro de la teoría y la práctica de la enseñanza y del aprendizaje de la música. España: Morata. Recuperado de https://dialnet.unirioja.es/servlet/libro?codigo=361563

Seidner W. y Wendler J. (1982). La voz del cantante. Henschel Arte y Sociedad. Berlín. 